\title{
Regeneration of Plant through Embryo Culture from Promising Maize (Zea mays L.) Inbred Lines
}

\section{Most Moriom Pervin' ${ }^{1}$ Md Abul Kalam Azad ${ }^{1}$, Md Arifuzzaman ${ }^{1 *}$, Md Ashiqur Rahman', Shahriar Rahman Shovon1 and Md Kaisar Ali ${ }^{2}$}

${ }^{1}$ Department of Genetics and Plant Breeding, Hajee Mohammad Danesh Science and Technology University, Bangladesh

${ }^{2}$ Department of Entomology, Hajee Mohammad Danesh Science and Technology University, Bangladesh

*Corresponding Author: Md Arifuzzaman, Professor, Department of Genetics and Plant Breeding, Hajee Mohammad Danesh Science and Technology University, Bangladesh.

Received: September 12, 2019; Published: October 18, 2019

DOI: 10.31080/ASAG.2019.03.0684

\section{Abstract}

The experiment was conducted with six selected inbred lines of maize (Zea mays L.) viz. ML-15, ML-10, ML-8, ML-28, ML-22 and ML-9 to assess regeneration ability from immature embryo at the tissue culture laboratory of the department of Genetics and Plant breeding, Hajee Mohammad Danesh Science and Technology, Dinajpur, Bangladesh from November 2017 to February 2018. Here, four different concentrations and combinations of hormones viz. $1.0 \mathrm{mgl}^{-1}$ 2,4-D (2,4-Dichlorophenoxyacetic Acid), $1.0 \mathrm{mgl}^{-1}$ BAP (6-Benzyl Amino Purine), $1.0 \mathrm{mgl}^{-1}$ Kinetin and BAP (1.0 $\left.\mathrm{mgl}^{-1}\right)+$ Kinetin $\left(1.0 \mathrm{mgl}^{-1}\right)$ supplemented with N6 (Chu) medium were used for embryogenic callus formation and plantlet regeneration. The inbred lines ML15, ML22 and ML9 revealed 100\% direct somatic embryogenesis (germination) under treatments BAP $\left(1.0 \mathrm{mgl}^{-1}\right)+$ Kinetin $\left(1.0 \mathrm{mgl}^{-1}\right)$, Kinetin $\left(1.0 \mathrm{mgl}^{-1}\right)$ and control treatments, respectively. The root length among the regenerated plantlet ranged from 0.66 to $4.83 \mathrm{~cm}$. Here, the longest root length was recorded in inbred line ML10 $(4.83 \mathrm{~cm})$ under 2,4-D $\left(1.0 \mathrm{mgl}^{-1}\right)$ treatment. The shoot length was ranged from 1.40 to $5.43 \mathrm{~cm}$. The inbred line ML15 of BAP $\left(1.0 \mathrm{mgl}^{-1}\right)$ treatment exhibited maximum shoot length $(5.43 \mathrm{~cm})$ followed by ML15 of treatment BAP $\left(1.0 \mathrm{mgl}^{-1}\right)+\mathrm{Kinetin}^{-}$ $\left(1.0 \mathrm{mgl}^{-1}\right)$.After hardening, the highest establishment rate was observed on ML10 as $100 \%$ under all treatment derived plants. And the plantlet derived from BAP and Kinetin combinations produced the maximum establishment rate (100\%) for all the genotypes. The maximum root length was observed from 2,4-D regenerated inbred line ML15 $(5.8 \mathrm{~cm})$ followed by the same genotype $(5.5 \mathrm{~cm})$ from BAP and Kinetin combinations. The plantlet derived from BAP and Kinetin revealed maximum shoot length by genotype ML9 $(9.2 \mathrm{~cm})$. Overall, in pot conditions, the superior shoot length performances were recorded in inbred regenerated plants from BAP + Kinetin and BAP treatments. Among the six inbred line of maize, ML-10 of treatment 2, 4-D and ML-22 of treatment BAP were successfully established in soil with the highest survival rate (100\%). Again, the correlation studies revealed significant positive relationship between root length and shoot length. Considering the seedling vigour index, the genotype ML10 and ML 28 revealed superior index value in most of the treatments. Overall, the inbred lines ML10 and ML28 identified as superior genotypes for plant regeneration and the treatment combination BAP $\left(1.0 \mathrm{mgl}^{-1}\right)+$ Kinetin $\left(1.0 \mathrm{mgl}^{-1}\right)$ were identical for immature embryos generation. Furthermore, this novel protocol might play a significant role in overcoming further interspecific and intrageneric maize hybrids.

Keywords: Zea mays L.; Embryo Rescue; Embryo Culture; In vitro Condition

\section{Introduction}

Maize (Zea mays L.) is a member of the Gramineae or grass family. It is a monocotyledonous plant with a diploid chromosome number of $2 \mathrm{n}=2 \mathrm{x}=20$ [1]. It is a particularly convenient plant for genetic studies because it can readily be either self or cross-pollinated with large numbers of seeds per plant. Globally it is top ranking cereal in worldwide significance as human food, animal feed and fodder as well as source of large number of industrial products like corn starch and starch-based products, and fermentation and distillation industries [2]. Conventional breeding method is insufficient to satisfy the goal as it demands more land, labor and capital. It also takes a long time, seed dormancy, early abortion of embryo and also infection of several diseases occur [3,4]. Usually it is a lengthy process but embryo culture can shorten the breeding cycle by overcoming dormancy in seeds.
All maize tissue culture and transformation involves the use of immature zygotic embryos as an explants source for regeneration [5]. However, immature embryos are seasonally available and have strictly limited suitable duration of culture, 14-19 DAP [6]. During the past decades, many types of media have been developed for in vitro plant culture $[7,8]$ with different formulations for the specific plants and tissues[9]. The most commonly used media for potato maize embryo culture is N6 basal media [10]. In culture media plant growth regulators generally play a vital role in embryo culture. Exogenous auxins seems to be required for plant embryo growth in vitro [11]. Cytokinins, when used as the sole hormone, are effective or promote young embryo growth. However, they promote growth and differentiation of embryos when they are combined with auxins [12]. Many researchers have investigated different plant regeneration through mature or immature embryos using 
different nutrient media with different growth regulators in cereals [13]. Murín., et al. [14] reported that immature embryo culture produced lower frequencies than mature embryo culture. But immature embryo culture could reduce the breeding cycle and embryo abortion during seed development in crop plants.

Considering the above facts, the research hypothesis is that immature embryo of maize genotypes produces lower frequencies of regeneration. This should be overcome through assessing and using different combinations of nutrient media for immature embryo culture of maize under aseptic conditions. Ultimately, a protocol for higher frequencies of somatic embryogenesis might occur through immature embryo culture. So, the present investigation was conducted with aim to i) evaluate the embryo culture responses of selected inbred lines for incorporating in maize breeding programs, and ii) establish a suitable protocol for immature embryo culture in maize.

\section{Materials and Methods}

Experimental location, Duration and Materials

The study was conducted in the Tissue Culture Laboratory of the Department of Genetics and Plant Breeding, Hajee Mohammad Danesh Science and Technology University, Dinajpur during October 2016 to July, 2017. The experiment was conducted in a growth room and arranged in Completely Randomized Design (CRD) with three replications. The six inbred lines of maize (Zea mays L.) viz. ML-15, ML-10, ML-8, ML-28, ML-22, and ML-9were used in the present investigation

\section{Embryo dissection and explants culture}

Maize plants were grown under normal field conditions in November 2016. After 18 days of pollination, the cobs were dissected from the field grown plant and taken into the tissue culture laboratory. Embryo sacs surrounded by nucellus tissue and blocks of endosperm containing the immature embryos were isolated from the cob of maize. After isolation, the embryo was placed in a sterile petridish and a sterile scalpel was used to cut embryo. The immature embryos are carefully removed by a twisting motion using the tapered end of a stainless steel spatula. The immature embryo is normally located on the side of the caryopsis that faces the tip of the ear. The embryo size was 0.9-1.8 $\mathrm{mm}$ and washed thoroughly with double distilled water inside laminar airflow cabinet for surface sterilization. Immature embryos were first sterilized with $70 \%(\mathrm{v} / \mathrm{v})$ ethanol for one minute. The embryos were then rinsed twice with sterile distilled water. Afterwards the embryos were surface sterilized by immersing in $0.1 \% \mathrm{HgCl}_{2}$ solution containing three drops of tweenty-20 solution and then finally rinsed and washed four times with sterilized distilled water. The surface sterilized embryos were then placed on to sterile germination medium in conical flasks. The culture was then incubated in dark till the germination of embryos. These were then transferred to 12 hours light for normal seedling growth.

\section{Sub-culture and plant regeneration}

Subculture of the embryo for shoot regeneration

Subculture was done when the calli attained a size of about 20-25 $\mathrm{mm}$ in diameter. These calli were removed aseptically from tubes on a sterilized petridish and were cut into 4 to $5 \mathrm{~mm}$ pieces with a sharp sterile scalpel, the pieces were again cultured on freshly prepared medium containing different hormonal supplements, for shoot induction from the cells. The sub culturing media used in the present investigation were $\mathrm{N}_{6}$ containing different combinations and concentrations of 2, 4-D, Kinetin and BAP. The sub-cultured tubes were again incubated at $25 \pm 2^{\circ} \mathrm{C}$ with moderate light intensity. After shoot initiation, more light intensity was used for shoot elongation. In some cases, repeated sub cultures were needed for shoot differentiation. Repeated subcultures were done at least once in a fortnight into a fresh medium and incubated under the same temperature as mentioned previously.

\section{Subculture of the regenerated shoot for root induction}

The sub-cultured calli continued to proliferate and differentiated into shoots. When these shoots grew about 3-5 cm in length, they were rescued aseptically from the culture tubes and separated from each other and again culture on freshly prepared medium containing different combinations of hormonal supplements for root differentiation.

\section{Subculture of the regenerated shoot for root induction}

The sub-cultured calli continued to proliferate and differentiated into shoots. When these shoots grew about 3-5 cm in length, they were rescued aseptically from the culture tubes and separated from each other and again culture on freshly prepared medium containing different combinations of hormonal supplements for root differentiation.

\section{Transplantation}

In the present investigation the plantlets with sufficient root system were taken out from the culture tube. Agar attached to the root was gently washed out with running tap water. The plantlets transplanted to small pots containing garden soil, sands and cow dung in the ratio $1: 2: 1$. Immediately after transplantation, the plants along with pots were covered with moist polythene bag to prevent desiccation. To reduce sudden shock, the pots were kept in a controlled environment in growth room. The interior of the polythene bags were sprayed with water at every 24 hours to maintain higher humidity around the plantlets. At the same time, plantlets were also nourished with Hoagland's solution. After 2-3 days, the polythene bags were gradually perforated to expose the plants to natural environment. The polythene bags were completely removed after 7 to 10 days. The plantlets at this stage were placed in natural environment for 3-10 hours daily. Finally, after 15-20 days they were transferred to the field condition. 


\section{Data recording and statistical analyses}

To investigate the effect of different treatments on six inbred lines, data were collected on the following parameters: Percent plant regeneration, Days to shoot initiation, Days to root initiation, Root length $(\mathrm{cm})$, shoot length $(\mathrm{cm})$, percent plant establishment. Seedling vigor index was calculated by using the method of AbdulBaki and Anderson [15] and expressed as Ushahra and Malik [16]. The formula for calculating seed vigor index is given below:

Seed vigor index $=$ Germination percentage $\times$ Mean seedling length (rootlet and shoot let).

The data were initially recorded in MS excel sheet. Afterwards, the analysis of variance (ANOVA), the Duncan's Multiple Range Test (DMRT), descriptive statistics, correlation co-efficient were calculated using R statistics of version 3.5.1 [17].

\section{Result and Discussion}

Regeneration of plantlet under in-vitro conditions

The immature embryo of six inbred lines were cultured on N6 medium supplemented with different concentrations and combinations of growth regulators viz. 2,4-D $\left(0.5 \mathrm{mgl}^{-1}\right)$, BAP $\left(0.5 \mathrm{mgl}^{-1}\right)$, Kinetin $\left(0.5 \mathrm{mgl}^{-1}\right)$ and BAP $\left(0.5 \mathrm{mgl}^{-1}\right)+$ Kinetin $\left(0.5 \mathrm{mgl}^{-1}\right)$. The inoculated immature embryos increased its size and revealed direct somatic embryogenesis for all treatment conditions. After sub-culturing and plantlet establishment, the data were recorded on root length, shoot length and germination percentage of regenerated seedling. The analysis of variance for three morphological characters were analyzed to account of significance of variation prevailed in a particular character among the six inbred lines of maize forfour different culture media (Table 1). The analysis of variance revealed significant difference among variety, treatment and variety $\mathrm{x}$ treatment for all the parameters studied. Coefficient of variation in all the characters was less than $12 \%$.

\begin{tabular}{|l|c|c|c|c|}
\hline \multirow{2}{*}{$\begin{array}{l}\text { Sources of } \\
\text { variation }\end{array}$} & \multirow{2}{*}{$\begin{array}{c}\text { Degrees of } \\
\text { freedom } \\
\text { (df) }\end{array}$} & $\begin{array}{c}|c| \\
\text { Mermination } \\
\text { percentage } \\
\text { (\%) }\end{array}$ & $\begin{array}{c}\text { Root } \\
\text { length }\end{array}$ & $\begin{array}{c}\text { Shoot } \\
\text { length }\end{array}$ \\
\hline Genotype & 5 & $916.67^{* * *}$ & $1.95^{* * *}$ & $3.21^{* * *}$ \\
\hline Treatment & 4 & $208.33^{*}$ & $4.51^{* * *}$ & $7.25^{* * *}$ \\
\hline Replication & 2 & $20.83 \mathrm{~ns}$ & 0.14 & $0.15 \mathrm{~ns}$ \\
\hline $\begin{array}{l}\text { Genotype } \times \\
\text { Treatment }\end{array}$ & 20 & $437.50^{* * *}$ & $2.76^{* * *}$ & $2.17^{* * *}$ \\
\hline Error & 58 & 78.30 & 0.05 & 0.11 \\
\hline Total & 89 & & & \\
\hline CV\% & & 11.79 & 8.93 & 9.78 \\
\hline
\end{tabular}

Table 1: Analysis of variance (ANOVA) for three morphological traits on regenerated maize plantlets.

Here, ${ }^{*}, * *$ and *** indicates significant at 5\%, 1\%, 0.1\% levels of probability, respectively and NS indicates not significant.
The mean performances of three characters for 6 different inbred lines and treatment interactions of maize are presented in table 2 . The maximum germination percentage $(100 \%)$ was observed in two inbred lines of maize for different treatments viz. ML15 for BAP + Kinetin, ML8 for control, ML22 for Kinetin treatment and ML9 for control, while the minimum germination percentage $(50 \%)$ was recorded in ML15 under control treatment. Root length among different plantlets of the maize inbred lines varied significantly from each other. The maximum root length was recorded in ML10 $(4.83 \mathrm{~cm})$ under treatment 2,4-D (Figure 1) followed by ML15 $(4.50 \mathrm{~cm})$ under same treatment. The minimum root length $(0.66 \mathrm{~cm})$ was observed in ML10 for the treatment Kinetin. The maximum shoot length was found in ML15 $(5.43 \mathrm{~cm})$ with BAP treatment, while the minimum number of shoot length $(1.40$ $\mathrm{cm})$ was found in ML15 using Kinetin. The maize inbred line CML161 produced highest number of shoot per callus in both MS and N6 medium [18]. High frequency of regenerated shoot per calli was also reported in maize [19-21].

Hardening and establishment of regenerated plantlets in the pot

The regenerated plantlets with sufficient root system were transplanted into small pot covered with polythene paper for hardening. The small pots containing sand, cocopeat and loamy soil. The plantlets were nourished with Hoagland's solution and subsequently new leaves were starting to initiate. The hardening period were lasts for 15 days. After proper hardening, the data were recorded on establishment rate, root length and shoot length at 21 days age of pot nourished plants and placed on table 3 . The highest establishment rate was observed on ML10 as $100 \%$ under all treatment derived plants. It was followed by ML9 and ML28. ML8 and ML15 revealed comparatively lower survival rate under five treatment conditions. Again by comparing the treatments, the plantlet derived from BAP and Kinetin combinations produced the maximum establishment rate (100\%) for all the genotypes. It was followed by 2,4-D derived plantlets. The maximum root length was observed by ML15 $(5.8 \mathrm{~cm})$ derived from 2,4-D followed by the same genotype $(5.5 \mathrm{~cm})$ from BAP+ Kinetin. The lowest root length $(2.1 \mathrm{~cm})$ were recorded on ML10 derived from Kinetin. Overall, the plantlet derived from 2,4-D revealed superior performances for most of the genotypes. It can be postulated the 2,4-D has play a vital role to initiate root during immature embryo cultured on N6 media. The plantlet derived from BAP and Kinetin revealed maximum shoot length by genotype ML9 $(9.2 \mathrm{~cm})$. It is followed by ML15 $(7.0 \mathrm{~cm})$ by the derived from BAP treatment. The lowest shoot length for the pot established plants were recorded on ML15 derived from control cultured conditions. Overall, in pot conditions, the superior shoot length performances were recorded in inbred regenerated plants from BAP + Kinetin and BAP treatments. Some factors affecting maize mature embryos regeneration used maize elite in-bred line 178 and 0.5 mgL-1 6-BAP had significantly increased the frequency of plant regeneration in the regeneration medium 78\% [22]. The inferior shoot length was recorded under 


\begin{tabular}{|c|c|c|c|c|c|c|c|}
\hline \multirow{2}{*}{ Genotype } & Control & 2,4-D & BAP & Kinetin & BAP+ Kinetin & \multirow{2}{*}{ LSD } & \multirow{2}{*}{ Range } \\
\hline & \multicolumn{5}{|c|}{ Germination percentage (\%) } & & \\
\hline ML15 & $75.0 b-d$ & $66.7 c-d$ & $66.66 c-d$ & $75.0 \mathrm{~b}-\mathrm{d}$ & $100.0 \mathrm{a}$ & \multirow[t]{6}{*}{6.46} & \multirow[t]{6}{*}{$50.0-100.0$} \\
\hline ML10 & $50.0 \mathrm{e}$ & $75.0 \mathrm{~b}-\mathrm{d}$ & 75. b-d & $75.0 \mathrm{~b}-\mathrm{d}$ & $75.0 \mathrm{~b}-\mathrm{d}$ & & \\
\hline ML8 & $100.0 \mathrm{a}$ & $75.0 \mathrm{~b}-\mathrm{d}$ & 83.3a-c & $75.0 \mathrm{~b}-\mathrm{d}$ & $75.0 \mathrm{~b}-\mathrm{d}$ & & \\
\hline ML28 & $58.3 \mathrm{~d}-\mathrm{e}$ & 66.66d-e & $58.3 d-e$ & 66.66d-e & $58.33 \mathrm{~d}-\mathrm{e}$ & & \\
\hline ML22 & $75.0 c-d$ & $75.0 c-d$ & $66.7 d-e$ & $100.0 \mathrm{a}$ & $91.66 a-b$ & & \\
\hline ML9 & $100.0 \mathrm{a}$ & $75.0 c-d$ & $75.0 \mathrm{c}-\mathrm{d}$ & 66.66d-e & $75.0 \mathrm{c}-\mathrm{d}$ & & \\
\hline \multicolumn{8}{|c|}{ Root length $(\mathrm{cm})$} \\
\hline ML15 & $2.20 \mathrm{f}-\mathrm{h}$ & $4.50 \mathrm{a}$ & $3.73 \mathrm{~b}$ & $1.06 \mathrm{l}-\mathrm{m}$ & $2.93 c-e$ & \multirow[t]{6}{*}{0.158} & \multirow[t]{6}{*}{$0.66-4.83$} \\
\hline ML10 & $2.60 \mathrm{~d}-\mathrm{f}$ & $4.83 a$ & $2.86 \mathrm{c}-\mathrm{e}$ & $0.66 \mathrm{~m}$ & $1.66 \mathrm{i}-\mathrm{k}$ & & \\
\hline ML8 & $2.33 \mathrm{f}-\mathrm{g}$ & $2.8 \mathrm{c}-\mathrm{e}$ & $2.93 c-e$ & $1.36 \mathrm{k}-\mathrm{l}$ & $3.03 c$ & & \\
\hline ML28 & $1.66 \mathrm{i}-\mathrm{k}$ & $1.33 \mathrm{k}-1$ & $1.56 \mathrm{i}-\mathrm{k}$ & $3.06 \mathrm{c}$ & $1.80 \mathrm{~h}-\mathrm{j}$ & & \\
\hline ML22 & $2.83 c-e$ & $2.33 f-g$ & $1.50 \mathrm{j}-\mathrm{l}$ & $2.53 \mathrm{e}-\mathrm{f}$ & $1.50 \mathrm{j}-\mathrm{l}$ & & \\
\hline ML9 & $2.73 c-e$ & $3.73 \mathrm{~b}$ & $1.83 \mathrm{~h}-\mathrm{j}$ & $3.0 \mathrm{c}-\mathrm{d}$ & $1.96 \mathrm{~g}-\mathrm{i}$ & & \\
\hline \multicolumn{8}{|c|}{ Shoot length $(\mathrm{cm})$} \\
\hline ML15 & $2.40 \mathrm{k}-1$ & $4.50 \mathrm{~b}-\mathrm{d}$ & $5.43 a$ & $1.43 \mathrm{~m}$ & $4.83 \mathrm{~b}-\mathrm{c}$ & \multirow[t]{6}{*}{0.245} & \multirow[t]{6}{*}{$1.40-5.43$} \\
\hline ML10 & $2.43 \mathrm{k}-\mathrm{l}$ & $4.33 \mathrm{~b}-\mathrm{d}$ & $3.50 \mathrm{f}-\mathrm{i}$ & $3.0 \mathrm{~h}-\mathrm{k}$ & $2.96 \mathrm{i}-\mathrm{k}$ & & \\
\hline ML8 & $2.01-\mathrm{m}$ & $4.50 \mathrm{~b}-\mathrm{d}$ & $3.90 \mathrm{~d}-\mathrm{g}$ & $2.46 \mathrm{k}-\mathrm{l}$ & $3.93 \mathrm{~d}-\mathrm{f}$ & & \\
\hline ML28 & $3.0 \mathrm{~h}-\mathrm{k}$ & $2.66 \mathrm{j}-\mathrm{k}$ & $3.30 \mathrm{~g}-\mathrm{i}$ & $1.40 \mathrm{~m}$ & $3.93 \mathrm{~d}-\mathrm{f}$ & & \\
\hline ML22 & $3.0 \mathrm{i}-\mathrm{k}$ & $3.33 f-i$ & $2.96 \mathrm{i}-\mathrm{k}$ & $3.63 e-h$ & $3.0 \mathrm{i}-\mathrm{k}$ & & \\
\hline ML9 & $3.16 \mathrm{~h}-\mathrm{j}$ & $4.66 \mathrm{~b}-\mathrm{c}$ & $4.23 c-e$ & $4.93 a-b$ & $3.90 \mathrm{~d}-\mathrm{g}$ & & \\
\hline
\end{tabular}

Table 2: Effect of inbred line $\times$ treatment interaction on root length $(\mathrm{cm})$, shoot length $(\mathrm{cm})$ and germination percentage $(\%)$ on regenerated plantlet in maize inbred lines.

\begin{tabular}{|c|c|c|c|c|c|c|c|}
\hline \multirow{2}{*}{ Parameters } & \multirow{2}{*}{$\begin{array}{l}\text { Treatment (during } \\
\text { initial culture) }\end{array}$} & \multicolumn{6}{|c|}{ Different inbred line of maize } \\
\hline & & ML15 & ML10 & ML8 & ML28 & ML22 & ML9 \\
\hline \multirow{5}{*}{$\begin{array}{l}\text { Establishment } \\
\text { rate (\%) }\end{array}$} & Control & $91.7 \pm 8.3$ & $100 \pm 0$ & $91.7 \pm 8.3$ & $100 \pm 0$ & $91.7 \pm 0$ & $100 \pm 0$ \\
\hline & 2,4-D & $100 \pm 0$ & $100 \pm 0$ & $91.7 \pm 0$ & $100 \pm 0$ & $83.3 \pm 0$ & $100 \pm 0$ \\
\hline & BAP & $91.7 \pm 8.3$ & $100 \pm 0$ & $100 \pm 0$ & $91.7 \pm 8.3$ & $100 \pm 0$ & $100 \pm 0$ \\
\hline & Kinetin & $91.7 \pm 8.3$ & $100 \pm 0$ & $83.3 \pm 8.3$ & $100 \pm 0$ & $100 \pm 0$ & $91.7 \pm 8.3$ \\
\hline & BAP+ Kinetin & $100 \pm 0$ & $100 \pm 0$ & $100 \pm 0$ & $100 \pm 0$ & $100 \pm 0$ & $100 \pm 0$ \\
\hline \multirow{5}{*}{$\begin{array}{l}\text { Root length } \\
(\mathrm{cm})\end{array}$} & Control & $3.5 \pm 0.03$ & $3.8 \pm 0.03$ & $3.7 \pm 0.07$ & $2.9 \pm 0.07$ & $4.0 \pm 0$ & $3.7 \pm 0.07$ \\
\hline & 2,4-D & $5.8 \pm 0.09$ & $5.4 \pm 0.07$ & $3.5 \pm 0.03$ & $3.2 \pm 0.17$ & $3.3 \pm 0.15$ & $4.2 \pm 0.12$ \\
\hline & BAP & $4.9 \pm 0.07$ & $4.5 \pm 0.12$ & $4.4 \pm 0.06$ & $3.2 \pm 0.07$ & $3.0 \pm 0.08$ & $3.8 \pm 0.12$ \\
\hline & Kinetin & $3.9 \pm 0.09$ & $2.1 \pm 0.07$ & $3.0 \pm 0$ & $4.1 \pm 0.07$ & $3.8 \pm 0$ & $4.8 \pm 0.08$ \\
\hline & BAP+ Kinetin & $5.5 \pm 0.17$ & $3.6 \pm 0.07$ & $4.4 \pm 0.21$ & $3.3 \pm 0.06$ & $3.2 \pm 0.14$ & $4.6 \pm 0.23$ \\
\hline \multirow[t]{5}{*}{ Shoot length } & Control & $3.5 \pm 0.06$ & $3.8 \pm 0.03$ & $3.9 \pm 0.07$ & $4.7 \pm 0.09$ & $3.8 \pm 0.09$ & $4.7 \pm 0.12$ \\
\hline & 2,4-D & $5.7 \pm 0.15$ & $5.8 \pm 0.088$ & $6.9 \pm 0.10$ & $5.5 \pm 0.29$ & $5.1 \pm 0.07$ & $5.7 \pm 0.12$ \\
\hline & BAP & $7.0 \pm 0.12$ & $5.9 \pm 0.07$ & $6.8 \pm 0.10$ & $6.8 \pm 0.10$ & $5.9 \pm 0.09$ & $6.2 \pm 0.18$ \\
\hline & Kinetin & $4.9 \pm 0.03$ & $5.4 \pm 0.09$ & $4.6 \pm 0.30$ & $3.9 \pm 0.06$ & $6.8 \pm 0.12$ & $6.5 \pm 0.09$ \\
\hline & BAP+ Kinetin & $6.8 \pm 0.12$ & $5.8 \pm 0.15$ & $5.8 \pm 0.17$ & $4.9 \pm 0.10$ & $4.8 \pm 0.93$ & $7.2 . \pm 0.17$ \\
\hline
\end{tabular}

Table 3: Hardening and establishment of regenerated plantlets of six inbred lines derived from five treatments $(\% \pm$ SE).

control derived plantlets Grando., et al. [23], conducted an experiment with four genotype of maize and only Hs1 genotype produce roots (42\%) from shoot derived calli and $69 \%$ of these were acclimatized.

\section{Survival of regenerated plants}

Interaction effect of different inbred line of maize and treatment showed significant variations on survival rate under in vitro condition (Table 4). The maximum survival rate (100\%) was found in the two inbred lines of maize derived from different treatments viz. ML 10 for 2, 4-D (Figure 1); ML22 for BAP, while the minimum survival rate (22.22\%) was found in ML15 (Figure 1) when Kinetin treatment was used in the culture vial and also the minimum survival rate $(22.22 \%)$ was found in ML8 when BAP treatment was used in the culture vial El-Itriby., et al. [5] observed that the inbred line $\mathrm{Gz} 643$ was the best line, revealing the highest regeneration frequency $(42.2 \%)$. 


\begin{tabular}{|l|c|c|c|c|c|}
\hline \multirow{2}{*}{ Genotype } & \multicolumn{5}{|c|}{ Survival rate (\%) } \\
\cline { 2 - 6 } & Control & 2,4-D & BAP & Kinetin & BAP+ Kinetin \\
\hline ML15 & $77.77 \mathrm{a}-\mathrm{d}$ & $44.44 \mathrm{e}-\mathrm{i}$ & $77.77 \mathrm{a}-\mathrm{d}$ & $22.22 \mathrm{i}$ & $55.55 \mathrm{~d}-\mathrm{i}$ \\
\hline ML10 & $33.33 \mathrm{~g}-\mathrm{i}$ & $100 \mathrm{a}$ & $55.55 \mathrm{~d}-\mathrm{i}$ & $88.88 \mathrm{a}-\mathrm{c}$ & $88.88 \mathrm{a}-\mathrm{c}$ \\
\hline ML8 & $66.66 \mathrm{~b}-\mathrm{f}$ & $55.55 \mathrm{~d}-\mathrm{i}$ & $22.22 \mathrm{i}$ & $33.33 \mathrm{~h}-\mathrm{i}$ & $55.55 \mathrm{~d}-\mathrm{i}$ \\
\hline ML28 & $66.66 \mathrm{~b}-\mathrm{g}$ & $33.33 \mathrm{~h}-\mathrm{i}$ & $44.44 \mathrm{f}-\mathrm{i}$ & $44.44 \mathrm{f}-\mathrm{i}$ & $55.55 \mathrm{c}-\mathrm{i}$ \\
\hline ML22 & $44.44 \mathrm{f}-\mathrm{i}$ & $55.55 \mathrm{~d}-\mathrm{i}$ & $100 \mathrm{a}$ & $33.33 \mathrm{i}$ & $44.44 \mathrm{f}-\mathrm{i}$ \\
\hline ML9 & $66.66 \mathrm{c}-\mathrm{h}$ & $44.44 \mathrm{f}-\mathrm{i}$ & $33.33 \mathrm{i}$ & $44.44 \mathrm{f}-\mathrm{i}$ & $22.22 \mathrm{i}$ \\
\hline LSD & \multicolumn{5}{|l}{} \\
\hline Range & \multicolumn{7}{|c}{$22.22-100$} \\
\hline
\end{tabular}

Table 4: Effect of inbred line $\times$ treatment interaction on survival rate of immature embryo in maize.

\section{Correlation}

A thorough understanding of the interaction of characters among themselves had been of great use in plant breeding. The efficiency of selection mainly depends on the direction and magnitude of association between component characters and also among themselves. Character association provides information on the nature and extent of association between pairs of metric traits and helps in selection for the improvement of the character. Correlations were worked out on traits viz. root length, shoot length, and germination percent collected on different maize inbred lines which was discussed in the results presented in (Table 5 and 6).

\begin{tabular}{|l|c|c|c|}
\hline Correlation & Germination (\%) & Root length & Shoot length \\
\hline $\begin{array}{l}\text { Germination } \\
(\%)\end{array}$ & - & 0.08 & 0.04 \\
\hline Root length & & - & $0.53^{* * *}$ \\
\hline Shoot length & & & - \\
\hline
\end{tabular}

Table 5: Correlations among important characters of maize in lab condition.

Here, ${ }^{* * *}$ indicates significant at $0.1 \%$ levels of probability.

\begin{tabular}{|l|c|c|c|c|}
\hline \multicolumn{1}{|c|}{ Correlation } & $\begin{array}{c}\text { Establishment } \\
\text { (\%) }\end{array}$ & $\begin{array}{c}\text { Root } \\
\text { length }\end{array}$ & $\begin{array}{c}\text { Shoot } \\
\text { length }\end{array}$ & $\begin{array}{c}\text { Survival } \\
\text { rate }\end{array}$ \\
\hline $\begin{array}{l}\text { Establishment } \\
(\%)\end{array}$ & - & 0.18 & 0.17 & 0.10 \\
\hline Root length & & - & $0.35^{*}$ & -0.12 \\
\hline Shoot length & & & - & -0.14 \\
\hline Survival rate & & & & - \\
\hline
\end{tabular}

Table 6: Correlations among important characters

$$
\text { of maize in pot condition. }
$$

Here, * indicates significant at $5 \%$ levels of probability.

In laboratory condition among the traits shoot length (0.53) exhibited positive and significant correlation with root length and positive and non-significant correlation with germination percent. On the other- hand root length (0.02) exhibited positive and significant correlation with germination but positive and non-significant correlation with shoot length showed in the table 5 .

In pot condition among the traits percentage of establishment exhibited positive correlation with root length $(0.18)$, shoot length and survival rate. The survival rate was negative and insignificant with root length $(-0.12)$ and shoot length $(-0.14)$. On the otherhand shoot length $(0.35)$ exhibited positive and significant correlation with root length. Ali., et al. [24] observed significant genotypic and phenotypic correlations between root and shoot length in maize.
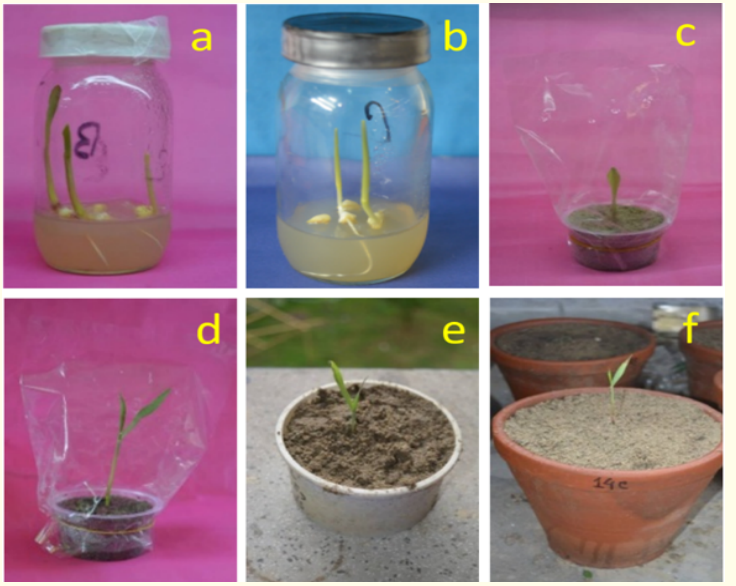

Figure 1. Plant regeneration from immatute embryo of maize inbred lines. (a)Initiation of shoot and root from immature embryo of ML28 in N6 + BAP (0.5mgl-1); (b) Initiation of shoot and root from immature embryo of ML10 in N6 + 2,4-D (0.5mgl-1); (c) Hardening of regenerated plantlet of ML22 after transplantation into small pot; (d) Hardening of regenerated plant of ML28 after transplantation into small pot; (e) Survived plant after hardening of ML15 derived from immature embryo of maize; (f) Survived plant after hardening of ML10 derived from immature embryo of maize.

\section{Seedling vigor index}

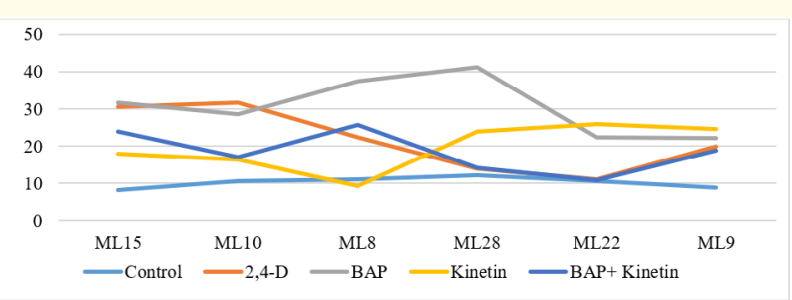

Figure 2: Seedling vigor index of different inbred line of maize under different hormonal combination. 
Seedling vigor is the combination of characteristics that determine the potential for high performance after sowing. Here, under the control condition ML28 inbred line of maize showed higher seedling vigor index and ML15 showed lower seedling vigor index. Statistically significant variation was also observed under the treatment of treatment 2, 4-D among different inbred line of maize respectively viz. ML 15 showed higher seedling vigor index and ML22 showed lower seedling vigor index in the same treatment. In the hormonal condition of BAP, highest seedling vigor index observed in the inbred line of maize ML 22 and lowest seedling vigor index observed in the inbred line of maize ML9. Seedling vigor index among different inbred lines of maize under kinetin hormonal condition varied significantly from each other and presented in Figure 2. The maximum number of seedling vigor index observed in the inbred line of ML22 and minimum seedling vigor index observed in the inbred line ML8. The last hormonal combination of BAP + kinetin, ML8 showed maximum seedling vigor index and ML22 showed minimum seedling vigor index. Highest seedling vigour index observed on genotype V13 among 15 maize inbred lines [25].

\section{Conclusion}

In this experiment, in vitro regeneration potentiality of six inbred line has been observed by using immature embryos as explant. Since genetic engineering developed the efficient methods for the regeneration of viable shoot from cultured tissues, this protocol can be followed for genetic manipulation for improvement of maize hybrids. Further study is needed to determine suitable explant and hormonal combination and concentration for other hybrid inbred line of maize of Bangladesh and by changing the hormonal concentrations and composition, type of media and trying by adding additional growth regulators could make a detailed investigation.

\section{Bibliography}

1. Bajaj. "Somaclonal variation - origin, induction, cryopreservation, and implications in plant breeding". In Somaclonal variation in crop improvement. Springer, Berlin, Heidelberg (1990): 3-48.

2. Wada., et al. "Maize in Asia changing markets and incentives". Academic Foundation, New Delhi (2008): 27-75.

3. King., et al. "In vitro genetics of cereals: problems and perspectives". Physiology 16 (1978): 381 -399.

4. Sheridan F. "Maize for biological research". University of North Dakota Press, Grand Forks, ND (1982).

5. EL-Itriby., et al. "Regeneration and transformation of Egyptian maize inbred lines via immature embryo culture and a biolistic particle delivery system". In vitro Cellular and Developmental Biology - Plant 39.5 (2003): 524-531.

6. Odour., et al. "In vitro Regeneration of dry Land Kenyan maize Genotypes through somatic Embryo genesis". International Journal of Botany 2.2 (2006): 146-151.
7. Pierik RLM. "In vitro culture of higher plants". Martinus Nijhoff publishers, Dordecht. (1989).

8. Torres KC. "Tissue culture techniques for horticultural crops". Van Nostrand Reinhold, New York (1989): 285.

9. Conger BV. " Cloning agricultural plants via in vitro techniques". CRC Press, Boca Raton, FL (1981).

10. Chu CC. "The $\mathrm{N}_{6}$ medium and its application to anther culture of cereal crops, in Plant Tissue Culture". Proceedings of the Peking Symposium (1981): 43-50.

11. Norstog K. "Embryo culture as a tool in the study of comparative and developmental morphology". In: W.R. Sharp, P.O. Larsen, E.F. Paddock, and V. Raghavan (eds.). Plant cell and tissue culture. Ohio State University Press, Columbus (1979): 179202.

12. Veen H. "The effect of various growth-regulators on embryos of Capsella bursapastoris growing in vitro". Acta Botanica Neerlandica 12 (1963): 129-171.

13. Bila., et al. "A Mini Review on Tissue Culture Responses of Some auspicious Wheat (Triticum aestivum L.) cultivars in different Media, Salts and Growth hormones 6. Department of Plant Breeding and Genetics". PMAS Arid Agriculture University, Rawalpindi, Pakistan 3.2 (2016): 370-374.

14. Murín R., et al. "Regeneration of immature and mature embryos from diverse sets of wheat genotypes using media containing different auxins". Acta Agronomica Hungarica 60.2 (2012): 97-108.

15. Abdul-Baki AA and JD Anderson. "Vigor determination in soybean and seed multiple criteria". Crop Science 13 (1973): 630633.

16. UshahraJ and CP Malik. "Putrescine and ascorbic acid mediated enhancement in growth and antioxidant status of Eruca sativa varieties”. CIB Tech Journal of Biotechnology 2 (2013): 53-64.

17. R Team Core. "R: a language and environment for statistical computing. R Found”. Stat. Comput. Vienna, Austria (2018).

18. Shohael., et al. "Somatic Embryogenesis and Plant Regeneration from Immature Embryo Derived Callus of Inbred Maize (Zea mays L.)". Biotechnology 2.2 (2003): 154-161.

19. Bohorova NE., et al. "Regeneration potential of tropical subtropical midaltitude and highland maize inbreds". Maydica 40 (1995): 275-281.

20. Carvalho CHS., et al. "Type II callus production and plant regeneration in tropical maize genotypes". Plant Cell Reports 17 (1997): 73-76. 
21. Das UR., et al. "Somatic embryogenesis and regeneration of plantlet from immature embryos of maize (Zea mays L.)". Plant Tissue Culture and Biotechnology 11 (2001): 65-75.

22. Xiang Y., et al. "Establishment of Plant Regeneration System from Mature Embryos of Maize Elite Inbred Line”. Acta Laser Biology Sinica 16.5 (2007): 649-654.

23. Grando., et al. "Immature tassels as alternative explants in somatic embryogenesis and plant regeneration in south Brazilian maize genotypes". Acta Scientiarum Agronomy 35.1 (2013): 39-47.

24. Ali., et al. "Studies of genetic variability and correlation among morphological traits of maize (Zea mays L.) at seedling stage". Albanian Journal of Agricultural Sciences 12.3 (2013): 405410.

25. Adebisi MA., et al. "Seed and seedling vigour in tropical maize inbred lines". Plant Breeding and Seed Science 67 (2013): 87102.

\section{Volume 3 Issue 11 November 2019}

(c) All rights are reserved by Md Arifuzzaman., et al. 